\title{
Editoração científica: as duas faces - analógica e digital
}

\author{
Scientific publishing: the two faces - analogic and digital
}

\author{
Carlos Teixeira Brandt* \\ *Professor Titular e Coordenador da Disciplina de Cirurgia. Pediátrica da Universidade Federal de Pernambuco [UFPE], Doutor, Livre \\ docente. Pesquisador Nível I do CNPq. \\ Presidente da Regional de Pernambuco da Sobradpec.
}

RESUMO: A Associação Brasileira de Editores Científicos (ABEC) promoveu, em setembro de 2004, o III Workshop de Editores Científicos em Recife. O enfoque principal foi sobre a forma de divulgação do conhecimento científico: analógico ou digital. Contudo, foram também discutidas as formas de financiamento da produção e divulgação desse conhecimento. A importância maior na produção do conhecimento esteve associada aos institutos de pesquisa, as universidades e as sociedades científicas. Tem sido observada uma tendência ao aumento no gerenciamento eletrônico da editoração e a informatização da divulgação; sobretudo pelo menor custo e maior facilidade; se os recursos humanos das ciências da informação estiverem disponíveis, todavia, a convivência da formatação analógica e digital é esperada por bastante tempo. Foi apresentada a idéia de um sítio eletrônico dos editores, com certificação digital, para que os autores da produção do conhecimento pudessem, com mais facilidade enviar os seus manuscritos. A seleção pelo corpo editorial das revistas desses manuscritos e a participação do corpo editorial na orientação da elaboração dos mesmos foi enfatizada. Essa atitude poderia aumentar a publicação do conhecimento produzido, particularmente daquele advindo dos programas de pós-graduação das universidades. Durante todo o evento ficou evidente a essencialidade da produção do conhecimento como elemento básico de evolução da própria sociedade humana.

Descritores: Editoração. Publicação eletrônica.

ABSTRACT: The Brazilian Association for the Scientific Editors (ABEC) promoted in September, 2004, the III Workshop for the Scientific Editors in Recife, Pernambuco - Brazil. The main focus was in the way that the scientific knowledge needs to be spread out : analogical or digital. However, the financial support for the production and the divulgation of this knowledge was also discussed. In the production it was agreed that it is made in the research institutes; universities and scientific societies. It has been observed a trend towards the electronic management of the publishing steps and the divulgation. Especially because a lower cost and greater facility; if the human resources of the information sciences are available; however, both form of publishing (analogical and digital) are expected to live side by side for some time to come. It was presented an idea of an electronic site for the scientific editors, with the safety of digital certification, where the authors could send their manuscript in an easier way. The scientific paper selection would be made by the editorial board of several scientific journals, which would provide some orientation for the authors in how to improve those manuscripts. It is hoped that this approach would allow an increase in the divulgation of science, especially the one produced in the university post graduation courses. It was evident, throughout the meeting the essentiality of the knowledge production as basic element for the evolution of the human society.

Key words: Publishing. Electronic publishing.

A Associação Brasileira de Editores Científicos (ABEC) promoveu entre 22 e 24 de setembro o III Workshop de Editores Científicos. A Acta Cirúrgica Brasileira esteve representada na mesa redonda "Experiências inovadoras de algumas revistas científicas brasileiras". O evento, como os anteriores, contribuiu, não só para atualizar os diferentes formatos de editoração e divulgação do conhecimento científico, assim como estimular a produção desse conhecimento.

As manifestações das exposições, e dos debates, foram no sentido de que os autores a produção da informação científica estão nas universidades, particularmente nos programas de pós-graduação, e institutos de pesquisa que são apoiados e estimulados pelas sociedades científicas1. Outros nichos de produção do conhecimento, com aparente sucesso, foram exemplificados em fundações e instituições privadas, que tendo suas próprias formas de divulgação desse conhecimento, mantêm periódicos institucionais com visibilidade muito pouco abrangente. Nesse sentido, observa-se que as posições da ABEC e da BIREME são de que esses conhecimentos ou sejam associados e divulgados em periódicos com maior consistência e, sobretudo, com maior visibilidade, ou de preferência sejam encaminhados para revistas da área do conhecimento já com maior tradição e visibilidade mais ampla. Assim sendo, percebese a falta de incentivo para que novas revistas sejam criadas. Há que se destacar que revistas tipicamente institucionais como a Revista do IMIP (Instituto Materno Infantil de Pernambuco), tendo recebido um forte apoio Institucional e mudando radicalmente o perfil transformou-se em uma revista de 
referência na Saúde Materno Infantil e encontra-se, vitoriosamente, indexada na base de dados SciELO, entre outros.

Em resumo, estaria em discussão o paradigma de quanto mais, melhor. $\mathrm{O}$ aumento do binômio, produção da informação científica e divulgação desse conhecimento, poderia estar prejudicado, se não houvesse o reconhecimento, pelos pares (corpo de revisores com isenção e alta credibilidade), da qualidade dessa informação. Nessa direção, o corpo editorial, das chamadas revistas institucionais ou regionais, poderia envolver vícios de origem, comprometendo o processo, que deve ser isento, dessa divulgação.

A agenda do Workshop incluiu o sistema de financiamento da editoração científica que envolveu, também, o financiamento da produção do conhecimento. Os destaques no financiamento dessas atividades mostraram a relevância do CNPq e da FINEP e de algumas FAPs (Fundações de Amparo a Pesquisa), particularmente a FAPESP de São Paulo. Foi lamentado que certas FAPs não venham participando desse importante passo na formulação de políticas de produção e divulgação de ciência; sem que elas se apercebam de que esse investimento é estratégico para o desenvolvimento do Estado, do País e da Sociedade. A complementaridade da CAPES na formação de recursos humanos foi também assinalada como fator importante nesse processo.

O fulcro de debate, contudo, esteve na forma de divulgação da informação científica. Os destaques, nesse debate, estiveram associados aos autores da ciência da informação. Particularmente, foram marcantes as contribuições de diversos membros do SEER (Sistema Eletrônico de Editoração de Revistas). Entre essas contribuições chamou atenção o conceito de sistema de incubação de publicação - incubadoras de publicação; o sistema informatizado de gerenciamento do processo de editoração das revistas científicas; a certificação digital como forma de proteção da propriedade intelectual, com a criação de cartórios editoriais; os chamados arquivos públicos abertos; e o periódico eletrônico.

Todos os assuntos das áreas de editoração e gerenciamento eletrônicos foram interessantes, contudo, embora os expositores das áreas da ciência da informação se esforçassem para mostrar a facilidade com que essas maravilhas da informática funcionam, e as vantagens que daí decorrem, ficou evidente, não só para o representante da Acta Cirúrgica, mas, para muitos outros editores há necessidade de pessoal especializado para trabalhar com essas ferramentas eletrônicas utilizadas na divulgação informatizada do conhecimento produzido. Em favor desses profissionais está a evidência cabal de que o processo digital demanda um investimento inicial um pouco mais alto, porém após a instalação torna o periódico eletrônico de custo menor.

Um problema não debatido, na profundidade devida, é se a publicação digital terá a mesma aceitabilidade e, na verdade, a mesma intensidade e prazer na leitura pelo usuário, do conhecimento divulgado pelo sistema de papel. Um complicador nesse tópico é que o manuscrito digital usa linguagem, Adobe por exemplo, que nem sempre está disponível no computador do usuário, que por vezes, mesmo tendo o programa tem dificuldade em seu manuseio. Pode ainda ser assinalado que o hardware de leitura pode ser custoso e a inovação dessa ferramenta se faz com um intervalo de tempo cada vez menor. Ainda mais, a revista em papel pode ser consultada nos locais os mais diversos, inclusive naqueles em que não se pode fazer uso de computador, mesmo nos menores palm tops. O que fica evidente, no momento atual, é que os dois sistemas -, analógico e digital deverão conviver por muito tempo; ou mesmo para sempre -, o que é um tempo muito longo e de difícil antecipação do que irá acontecer.

Para acrescentar uma análise pouco científica, pois o tamanho da amostra não tinha sido previamente calculado, em uma survey entre vinte colegas de duas instituições médicas de Recife, observou-se que 17 (85\%) preferiam a revista em papel e três, da área mais acadêmica, achavam indiferente. Uma idéia interessante que surgiu nessa investigação de pouca credibilidade é de que em sendo a revista no formato eletrônico houvesse a disponibilidade de separatas no papel.

Uma idéia pessoal, do representante da Acta Cirúrgica, na mesa redonda "Experiências positivas/inovadoras de algumas revistas científicas brasileiras" foi a de uma possível inversão, ou adequação, entre os autores da produção do conhecimento e os divulgadores do mesmo. Na teoria, a proposta funcionaria da seguinte forma. Um conjunto de editores abriria um site (sítio) onde os produtores do conhecimento colocariam eletronicamente os seus produtos, que seriam protegidos por certificado digital. Os editores estariam constantemente tomando conhecimento das informações lá alocadas. Aquelas que fossem de boa qualidade e de interesse para as suas revistas seriam selecionadas eletronicamente. Nessas circunstâncias, os produtores do conhecimento seriam informados do interesse da revista, das normas de publicação e das modificações necessárias para possível publicação. Em se concretizando as recomendações sugeridas o manuscrito seria, então, encaminhado para os pares revisores para eventual publicação. A idéia tem como objetivo dar maior agilidade ao processo de divulgação do conhecimento e, possivelmente, ajudar, sobretudo, os pós-graduandos no processo de elaboração do manuscrito a ser publicado.

Qual a pertinência ou vantagens da idéia? Cerca de $80 \%$ do conhecimento produzido nos programas de PósGraduação ficam nas teses, nos arquivos empoeirados das bibliotecas Institucionais. Isso ocorre por diversas razões. A mais importante talvez seja o fato de que o pós-graduando ao defender a tese e obter o grau a que tem direito, acredite de forma errônea, que sua missão esteja concluída. Contudo, o prejuízo é grande para a Instituição, para o orientador e talvez para a própria Ciência. É verdade que existem mudanças, já em curso, que obrigam os pós-graduandos a só defenderem suas teses após publicação dos trabalhos científicos nelas contidas. Todavia, o intervalo de tempo entre a submissão desses artigos, nas melhores revistas, pode ultrapassar um ano, o que alonga muito o tempo de pós-graduação, podendo interferir no próprio conceito do Programa.

Uma dificuldade nessa idéia é a manutenção do sigilo da informação que ficaria no sitio dos editores. Pode-se imaginar que com essa informação armazenada em sistema informatizado 
poderia estar vulnerável a hackers e, eventualmente, servir de base para que pessoas inescrupulosas fizessem uso dessa propriedade e produzissem em tempo "oportuno" as suas próprias teses -, o que seria lamentável. A informação, colocada no evento pelo Prof. Luiz Gustavo Cordeiro da Silva da UFPE, é de que com a certificação digital a segurança dessa atividade, assim como nos bancos comerciais, pode chegar a próximo de $100 \%$.

Uma análise pouco aprofundada do evento é de que ele foi muito proveitoso tanto para aqueles que editoram e divulgam o conhecimento, mas, também, para aqueles que simultaneamente participam do processo de produção desse instrumento necessário para o desenvolvimento da humanidade; a Ciência. Eventos similares precisam ser estimulados pelas instituições de pesquisa, universidades, sociedades científicas e todos os autores da produção do conhecimento. $\mathrm{O}$ apoio econômico para realização dos mesmos tem de receber prioridade dos órgãos de fomento à pesquisa e formação de recursos humanos na Academia -, CAPES, CNPq e FAPs. Isso é essencial; sem ele os sonhadores da investigação científica e os divulgadores desse bem precioso ficarão como arrimos de uma família muito bonita - os poetas das sociedades vivas.

\section{Referência}

1. Población DA, Goldenberg S, Montero EFS, Gomes PO, CampanatiOstiz H, Moreira MB, Santos AC, Pellizon RF. Revistas brasileiras publicadoras de artigos científicos em cirurgia. II - Terminologia e atribuições adotadas pelos editores. Proposta de organograma do periódico e fluxograma do artigo. Acta Cir Bras. 2003;18(6):497501. Disponível em URL: http://www.scielo.br/acb

Correspondencia:

Carlos Teixeira Brandt

Av. Boa Viagem, 5090/1201

51011-000 Recife - PE

carlosbrandt@bol.com.br

\section{Como citar este artigo:}

Brandt CT. Editoração científica: as duas faces - analógica e digital. Acta Cir Bras [serial online] 2004 Nov-Dez;19(6). Disponível em URL: http://www.scielo.br/acb [também em CD-ROM]. 